Int. J. Electrochem. Sci., 14 (2019) $1794-1808$

International Journal of

ELECTROCHEMICAL

SCIENCE

$\underline{\text { www.electrochemsci.org }}$

\title{
A Novel Photoelectrochemical Sensor Based on Gr-SiNWs-Si/Pt Electrode for Sensing of Hydroquinone
}

\author{
Hua Zhang ${ }^{1, *}$, Huaixiang Li $^{2}$, Jiao Li $^{1}$, Haibin Sun ${ }^{1}$, Lixia Zhou ${ }^{1}$, Ruihua Wang ${ }^{3}$ \\ ${ }^{1}$ School of Materials Science and Engineering, Shandong University of Technology, Zibo 255000, P.R. \\ China \\ ${ }^{2}$ College of Chemistry, Chemical Engineering and Materials Science, Shandong Normal University, \\ Jinan 250014, P. R. China \\ ${ }^{3}$ Library, Shandong Normal University, Jinan 250014, P. R. China \\ *E-mail: zhanghua01979@sdut.edu.cn
}

doi: $10.20964 / 2019.02 .33$

Received: 24 October 2018 / Accepted: 11 December 2018 / Published: 5 January 2019

\begin{abstract}
Herein, a graphene (Gr) and silicon nanowires (SiNWs) decorated n-silicon/platinum ( $\mathrm{Si} / \mathrm{Pt}$ ) sensor was put forward to detect hydroquinone (HQ) in a photoelectrochemical (PEC) way. Platinum film was coated on the polished side of the n-silicon wafer by vacuum evaporation and SiNWs were fabricated uniformly on the other side of the wafer by electrochemical etching in a solution mixed by $\mathrm{HF}$ and ethanol with volume ratio 1:1 under illumination of scattered laser. The morphology and component of the SiNWs was characterized by SEM and EDS, respectively. The photoelectric properties of the SiNWs-Si/Pt were studied by semi-log current-voltage $(\log I-V)$ and photoresponse measurements. Results show that the SiNWs on the Si wafer enhance the photoelectric conversion efficiency of the Si/Pt Schottky junction by about $33 \%$ relative to $\mathrm{Si} / \mathrm{Pt}$ without SiNWs. Then, graphene was prepared with Hummer method and was used to decorated the SiNWs-Si/Pt wafer to build a Gr-SiNWs-Si/Pt PEC sensor. The new sensor was used to detect HQ in a two-electrode PEC way at zero bias voltage in a linear range of $10-300 \mu \mathrm{M}$ with a detection limit of $0.3 \mu \mathrm{M}(\mathrm{S} / \mathrm{N}=3)$. Excellent selectivity of the sensor to HQ in the present of catechol (CC) and other interferences was proved by anti-interference experiment.
\end{abstract}

Keywords: Photoelectrochemical; Graphene; PEC sensor; Hydroquinone; Zero bias detection

\section{FULL TEXT}

(C) 2019 The Authors. Published by ESG (www.electrochemsci.org). This article is an open access article distributed under the terms and conditions of the Creative Commons Attribution license (http://creativecommons.org/licenses/by/4.0/). 